\title{
İşitme Engelli Hentbol Oyuncularının Benlik Saygısı Düzeylerinin İncelenmesi: Bir Örnek Olay
}

\author{
Investigation of Hearing Impaired Handball Players' Self-Esteem Symptom Levels: A Case Study
}

\author{
Merve Uca* - Ülkü Çoban**
}

\begin{abstract}
Self-esteem is one of the most researched areas within the framework of educational psychology, personality psychology and social psychology. However, disability as a social phenomenon has always been widely seen as a fundamental problem in terms of social relations. Particularly, the participation of disabled children in various sports activities, which play an important role in the development of their self-esteem, is quite limited. Therefore, the inability of hearing-impaired children to participate in various sports activities, which is one of the important basic critical elements of adolescence, causes their feelings of exclusion to increase and their self-esteem is negatively affected. The aim of this study is to examine the self-esteem symptom levels of handball players with hearing impairment. The data of the research conducted for this purpose were obtained in 2019 and the sample group consisted of a total of 78 people, 39 of whom were hearing impaired and 39 were in the control group. Demographic Structure Information Form and Rosenberg Self-Esteem Scale were used in the research. The obtained data were analyzed in SPSS program. As a result of the research, since the ANOVA significance value of the handball players in the hearing impaired and control groups is greater than 0.05 , it shows that there is no significant difference between the compared averages of the hearing impaired handball players and the non-hearing impaired (control group) handball players. This study has shown that hearing impaired people's participation in sports activities contributes positively to their self-esteem. As a result, no significant difference was found between disabled and nondisabled handball players in terms of self-esteem.
\end{abstract}

Structured Abstract: In recent years, studies on self-concept and self-esteem, which are among the main factors related to personality development, have begun to attract significant attention in revealing protective factors against various psychological problems. Self-esteem is emerging as a vital component for people's psychological health and life satisfaction. In addition, self-esteem as an element of emotional well-being is one of the important criteria of quality of life. In research on the self-esteem of deaf and hard-of-hearing children and youth, which is the subject of this study, researchers have revealed that they have a lower selfesteem than their peers who are not deaf or hard of hearing. It has been suggested that low self-esteem in deaf and hard of hearing children stems from difficulties in communication and failure to establish healthy relationships with their peers. The main purpose of this study; By measuring the self-esteem levels of deaf

\footnotetext{
* Dr. Öğr. Üyesi, İstnbul Aydın Üniversitesi, Spor Bilimleri Fakültesi, Beden Eğitimi ve Spor Öğretmenliği Bölümü Asst. Prof. Dr., Faculty Member, Istanbul Aydin University, Faculty of Sports Science, Department of Physical Education and Sports Teaching 
handball players and athletes in the control group; It is aimed to reveal whether there is a difference between the self-esteem of the hearing impaired handball players and the athletes (12-18 years old) in the control group. In addition, self-esteem scores will be examined according to various variables. In the comparison of both groups, we hypothesized that there would be no difference between the self-esteem of the handball players in the hearing-impaired and control group.

In a study on the mental and physical functioning of hearing-impaired people, it was found that there is a relationship between their self-esteem and their physical activities, that the self-esteem status of physically active disabled people is higher than that of sedentary individuals. It was found that there was a positive relationship between the components. In another study, the results obtained in studies evaluating gender differences in self-concept and self-esteem showed great differences, in studies showing gender differences, women had a lower self-concept, while other studies found no significant differences in selfconcept or self-esteem. Other studies have analyzed the links between self-concept/self-esteem and psychopathological symptoms in children and adolescents. It has been shown that inverse relationships between these constructs are pointed out, there are positive relationships between self-esteem and mental health, and there are relationships between self-concept dimensions and health-promoting behaviors and health-risk behaviors.

In the descriptive statistics part of the study, the results of the mean value (mean) and median (median) values for the normal distribution test are close to each other, indicating that the data set has a normal distribution. As seen in the study, our average value is 2.5744 and the median value is 2.4000 . According to these data, the data set is considered as a normal distribution. The Skewness and Kurtosis values are two values that should be checked for the normal distribution test. For Skewness and Kurtosis values to show a normal distribution, they must have values close to 0 or 0 . As can be seen from the ANOVA table, $(p)=$ sig. Since the value is greater than 0.05 , it shows that there is no significant difference between the compared averages of deaf handball players and non-deaf handball players. Other studies have found that higher levels of adolescent sports participation positively affect self-esteem, which is associated with lower levels of depression. Organized sports contribute significantly to the healthy development of young people by providing opportunities to learn athletic skills, peer relations and non-academic competencies, resulting in greater self-esteem. It also revealed that participation in sports can increase feelings of physical competence and satisfaction with physical appearance. It means that sport offers a sense of achievement that is an important part of adolescents' sense of self. For example, seeing that one's extra efforts are rewarded and achieving one's short- or long-term goals can build a body of self-esteem.

In this study; When the self-esteem of the athletes in the deaf and non-hearing control groups who do sports is examined, it is understood that there is no significant difference. This shows that doing sports has a significant positive effect on the development of self-esteem. Considering whether there is a significant difference in self-esteem between handicapped and non-disabled handball players, no significant difference was found, so the results show that hearing impaired athletes who play sports help the development of selfesteem.

As a result of the findings obtained in the study, it can be said that the self-confidence levels of the hearing impaired handball players in different living areas are at similar levels. It is important that there is no significant difference between the variables. This situation reveals the necessity of further examination of these results. Conflicting studies on hearing-impaired individuals have become an open subject for discussion, so the necessity of new and more studies emerges.

Keywords: Self-Esteem, HearingImpaired, Sports, Handball Player

Öz: Benlik saygısı, eğitim psikolojisi, kişilik psikolojisi ve sosyal psikoloji çerçevesinde en çok araştırma yapılan alanlardan biridir. Ancak toplumsal bir olgu olarak engellilik, toplumsal ilişkiler açısından her zaman yaygın olarak temel bir sorun olarak görülmüştür. Özellikle engelli çocukların benlik saygılarının gelişiminde önemli rol oynayan çeşitli spor etkinliklerine katılımları oldukça sınırlıdır. Dolayısı ile işitme engelli çocukların ergenlik döneminin önemli temel kritik unsurlarından biri olan çeşitli spor aktivitelerine katılamamaları onların dışlanma hislerinin artmasına ve benlik saygılarının olumsuz yönde etkilenmesine neden olmaktadır. Bu çalışmanın amacı hentbol oynayan işitme engelli sporcuların benlik saygı belirti düzeylerinin incelenmesidir. Bu amaçla yapılan araştırmanın verileri 2019 yılında elde edilmiş olup örneklem 
grubunda 39 işitme engelli ve 39 kontrol grubu olmak üzere toplam 78 kişiden oluşturulmuştur. Araştırma da Demografik Yapı Bilgi Formu ve Rosenberg Benlik Saygısı Ölçeği kullanılmıştır. Elde edilen veriler SPSS programında analiz edilmiştir. Araştırma sonucunda, işitme engelli ve kontrol gurubundaki hentbolcuların ANOVA anlamlılık değeri $(\mathrm{p})=$ sig. > 0,05 büyük olduğu için işitme engelli ve kontrol grubunda yer alan sporcuların karşılaştırılan ortalama değerleri arasında istatiksel olarak anlamlı olmadığı belirlenmiştir. Bu çalışma, işitme engellilerin spor aktivitelerine katılımlarının benlik saygısına olumlu yönde katkı sağladığını göstermiştir. Sonuç olarak engelli ve engelli olmayan hentbolcular arasında benlik saygısı açısından anlamlı bir fark bulunmamıştır.

Anahtar Kelimeler: Benlik Saygısı, İşitme Engelli, Spor, Hentbol

\section{Giriş}

Son yıllarda psikolojik sorunlara karşı koruyucu faktörlerin belirlenmesi bağlamında kişilik gelişimi ile ilgili ana unsurlardan biri olan benlik kavramı ve benlik saygısı üzerine yapılan araştırmalar önemli derecede dikkat çekmeye başlamıştır. Benlik saygısı, insanların psikolojik sağlı̆̆ 1 ve yaşam tatmini için çok önemli bir bileşen olarak ortaya çıkmaktadır (Rosenberg, 1965). Buna ek olarak duygusal iyi oluşun bir unsuru olarak benlik saygısı, yaşam kalitesinin boyutlarından biridir (Knox ve Muros, 2017). İşitme engelli ve işitme güçlüğü çeken çocuk ve gençlerin benlik saygısına ilişkin yapılan araştırmalarda işitme engelli olmayan ve işitme güçlüğü çekmeyen akranlarına kıyasla daha düşük bir benlik saygısına sahip olduklarını ortaya koymuşlardır (Lesar ve SmrtnikVituli, 2014). Bunun nedeni işitme engelli ve işitme güçlüğü çeken çocuklarda düşük benlik saygısının iletişimde güçlükler ve akranlarıyla sağlıklı ilişkiler kurmakta başarısız olmalarıdır (Fellinger vd., 2012).

Benlik saygısı, bireysel bilişsel, fiziksel ve sosyal becerilerin öznel öz değerlendirmesine dayanan çok boyutlu bir yapı olarak tanımlanmaktadır (Dzwonkowska vd., 2008). Benlik saygisının beden imaj1 (Muth ve Cash, 1997) ve beden tatmini (Frost ve McKelvie, 2004) gibi farklı boyutları tanımlanmış ve keşfedilmiştir. Bu alanlardaki değişiklikler, benlik saygısı düzeyini etkiler. Sonstroem ve Morgan (1989), fiziksel aktivitenin benlik saygısı ve küresel benlik saygıs1 boyutları üzerindeki etkisini analiz ederek Egzersiz Benlik Saygısı Modelini önermiştir. Araştırmacılar, fiziksel aktivite ile uğraşırken, benlik saygısının boyutlarında olumlu değiş̧iklikler olabileceğini ve bunun da küresel benlik saygısı seviyesini etkileyebileceğini varsaydılar. Ayrıca, fiziksel aktivite ile ilgili olarak, benlik saygısının öz-yeterlikten etkilenebileceğini belirtmişlerdir. $\mathrm{Bu}$ bulgu, benlik saygısının atletik yeterlilik ile pozitif yönde ilişkili olduğunu bulan Noordstar vd. (2016) ile tamamen uyuşmaktadır. Egzersiz Benlik Saygısı Modeline (Sonstroem ve Morgan, 1989) dayanarak, sağır çocuklar için benlik saygısının bileşenlerini belirlemek için titreşimli kulaklıkların kullanıldığı deneysel dans derslerinin etkisini test etmiştir.

Diğer yandan bireyler, doğdukları andan itibaren yaşadıkları toplumun içinde sosyal bir rol üstlenmeye ve üstlendikleri rolleri devam ettirme çabası içinde sürekli çalışırlar. Bu süreçte bireyin kendisine atfettiği değer, benlik duygusuyla doğrudan ilişkili kabul edilir. Her birey yaşamında belli rolleri yerine getirir. Benlik kavramı, bir kişinin bu rollerle ilgili olarak kendisini nasıl algıladığını ifade eder. Benlik saygısı, bireysel bilişsel, fiziksel ve sosyal becerilerin öznel öz değerlendirmesine dayanan çok boyutlu bir yapı olarak tanımlanır (Dzwonkowska vd., 2008). Bunun yanında, kendini kabul etme, kimlik oluşumu ve başkalarının kabulü anlamına da gelmektedir (Adams ve Gullotta, 1989). Benlik saygisının beden imaj1 (Muth ve Cash, 1997) ve beden tatmini (Frost ve McKelvie, 2004) gibi farklı boyutları tanımlanmış ve keşfedilmiştir.

Bu alanlardaki değişiklikler, benlik saygısı düzeyini etkiler. Sonstroem ve Morgan (1989), fiziksel aktivitenin benlik saygısı ve küresel benlik saygısı boyutları üzerindeki etkisini analiz ederek Egzersiz Benlik Saygısı Modelini önermiştir. Kişinin kendisi hakkındaki yargıları, büyük olasılıkla kendini tanıma sisteminin temel yapısını oluşturur. Bu yargıların iki türünden birisi olan 
tanımlayıcı yargılar, yaşı, cinsiyeti, mesleği, fiziksel özellikleri ve davranış biçimleri göz önünde bulundurulmak suretiyle kişinin gerçekte nasıl olduğunu ifade eder. İkinci türü olan değerlendirici yargılar, nitelikleri, onlar hakkında ne düşünüldüğü ile ilgili değerlendirilmelerle alakalıdır. Dolayısı ile benlik saygısı, benlik kavramının, öz bilginin değerlendirici kısmını oluşturur (Garaigordobil vd., 2008).

İşitme engelli kişilerin zihinsel ve fiziksel işleyişine ilişkin, Nemček (2017) tarafından yapılan bir araştırmada, benlik saygıları ile fiziksel aktiviteleri arasındaki bir ilişki olduğu, fiziksel olarak aktif engelli kişilerde benlik saygısı durumunun hareketsiz bireylere göre daha yüksek olduğunu bulmuştur. Ayrıca, Uchida ve arkadaşlarının (2015) çalışmalarında ise işitme engelli sporcularının yüksek performanslı fiziksel aktivitesi ile benlik saygısının bileşenleri arasında pozitif bir ilişki olduğunu doğrulamışlardır.

Benlik kavramı ve benlik saygısında cinsiyet farklılıklarını değerlendiren çalışmalarda elde edilen sonuçlar büyük farklılıklar göstermektedir. Cinsiyet farklılıklarını gösteren çalışmalarda, kadınların daha düşük benlik kavramına sahip oldukları bulunmuştur (Wilgenbush ve Merrel, 1999). Bununla birlikte, diğer çalışmalar benlik kavramında (Garaigordobil vd., 2003) ya da benlik saygısında önemli farklılıklar bulamamışlardır (Benjet ve Hernández, 2001; Lameiras ve Rodríguez, 2003; Matud vd., 2003).

Başka çalışmalarda çocuklar ve ergenlerde benlik kavramı / benlik saygısı ve psikopatolojik belirtiler arasındaki bağlantıları analiz edilmiştir. Bu yapılar arasındaki ters ilişkilere işaret edilmektedir. Benlik saygısı ve ruh sağlığ arasında olumlu ilişkiler olduğu ortaya konulmuştur (Yuang, 2000; Fan ve Fu, 2001). Benlik kavramı boyutları ile sağlığ geliştirici davranışlar ve sağlığı riskli davranışlar arasında ilişkiler bulunulmuştur (Pastor vd., 2006). Deneysel bir perspektiften hareketle, Gutiérrez vd. (2005), yüksek benlik saygısının katı bir şekilde benlik-yeterliliği koruduklarını göstermiştir. Diğer bir çalışma, düşük benlik saygısının kişilik bozukluklarının güçlü bir göstergesinin olduğunu bulmuştur (Watson, 1998).

Scarpa (2011), organize fiziksel aktivite biçimlerine katılmanın, engelli çocukların yeni zorlukları denemelerine imkân tanıdığını vurgulamıştır. Dahası, onlara beceriler ve hareket yetenekleriyle ilgili beklentileri güvenilir bir şekilde karşılama, yeterli benlik saygısı ve özgüvenlerini geliştirme firsatı sunar. Zorunlu bir şekilde spor ve boş zaman faaliyetlerine katılmak aynı zamanda hem başarı hem de başarısızlıkların yaşanması ile ilişkilidir. Pozitif olarak sosyal etkisi, bir kişinin fiziksel durum ve hareket becerilerine olan inancını ve sonuç olarak benlik saygısını artırabilir (Haugen vd., 2013). Yeni motor becerilerin edinilmesinin, işitme engelli çocuklar ile gençlerin rekreasyon ve spor faaliyetlerine katılımının artmasını teşvik edebileceği varsayılabilir. Buna karşıllk, artan fiziksel aktivite seviyesi, somatik parametrelerde olumlu değişikliklere yol açabilmekte ve fiziksel çekicilik alanında kısmi benlik saygısı seviyelerinin büyümesini etkileyebilmektedir. $\mathrm{Bu}$ süreçleri işitme engelli çocuklarının küresel benlik saygısı takip eder ( Lu vd., 2015).

\section{Yöntem ve Metot}

\subsection{Araştırmanın Amacı ve Hipotezi}

$\mathrm{Bu}$ çalışmanın temel amacı; İşitme engelli hentbolcular ve kontrol gurubunda yer alan sporcularda benlik saygısı düzeylerinin ölçülerek; işitme engelli hentbolcuların ve kontrol gurubundaki sporcuların (12-18 yaş gençlerin) benlik saygıları arasında fark olup olmadığının ortaya konması amaçlanmıştır. Ayrıca çeşitli değişkenlere göre benlik saygısı puanları incelenecektir. Her iki grubun karşılaştırılmasında işitme engelli sporcu ve kontrol gurubundaki hentbolcuların benlik saygısı arasında herhangi bir farklılık olmayacağı varsayımında bulunduk. 
Araştırmada işitme engelli ve kontrol gurubundaki hentbolcularının benlik saygısı puanları karşılaştırılarak; İşitme engelli sporcu ve kontrol gurubundaki sporcuların Benlik Saygısı Düzeylerinin benlik saygısı puanları ortalamalarında farklılık olup olmadığı incelenmiştir.

\subsection{Veri Toplama Araçları}

Araştırmada veri toplamak amacıyla, işitme engelliler federasyonuna bağlı engelli hentbolcular ve kontrol gurubunda yer alan engelli olmayan hentbolcuların bazı demografik özelliklerini belirlemek için araştırmacı tarafindan geliştirilen "Demografik Yapı Bilgi Formu", benlik saygılarını belirleyebilmek için "Rosenberg Benlik Saygısı Ölçeği” kullanılmıştır.

Araştırmada benlik saygısı ölçümü için kullanılan Rosenberg Benlik Saygısı Ölçeği Morris Rosenberg tarafından 1963 yılında geliştirilmiştir. Rosenberg (1965), Rosenberg Benlik Saygıs1 Ölçeği çoktan seçmeli sorulardan oluşturulmuş olup 12 alt kategoriden olmak üzere, 63 maddeli bir öz bildirim testidir. Bu çalışmada ölçeğin sadece "Benlik Saygısı" alt boyutu kullanılmıştır.

\subsection{Sinırlılıklar}

Araştırmaya katılanların ailelerinin gelir durumları, anne ve babanın mesleği, eğitimi, katılımcıların yaşı ve cinsiyetlerine göre benlik saygı düzeylerine bakılmamış olup, spor yapan işitme engelli ve spor yapan işitme engelli olmayan sporcuların benlik saygı düzeylerine odaklanılmıştır. Dolayısı ile işitme engelli sporcu ve işitme engelli olmayan sporcuların benlik düzeyleri karşılaştııılmıştır. Araştırma verileri 2019 yılında elde edilmiş olup, Araştırmaya işitme engelliler federasyonuna bağlı spor kulübü 39 işitme engelli hentbolcu ve kontrol gurubunda yer alan 39 hentbolcu dahil edilmiştir.

\subsection{Verilerin Analizi}

Rosenberg Benlik Saygısı Ölçeğinden elde edilen verilerin analizinde SPSS paket programı kullanılmıştır. Çalışmada güvenilirlik analizi için temel analiz olan Cronbach Alpha $(\alpha)$ kullanılmıştır. Örneklemin benlik saygısı düzeylerine ilişkin puanlarının engellilik durumuna göre test etmeden önce araştırma verilerinin normal dağılım özelliği taşıyıp taşımadığı KolmogorovSmirnov Testi ile tespit edilmiştir. Kolmogorov-Smirnov testi sonucunda verilerin normal dağılım özelliği göstermesinden dolayı engellilik durumuna göre farklılık olup olmadığına ilişkin ANOVA (normal dağılım) analiz yöntemleri kullanılmıştır.

\subsection{Bulgular}

İşitme engelli ve kontrol gurubu (işitme engelli olmayan) hentbolculara ait bulguların analiz ve değerlendirilmesi aşağıdaki tablolarda sunulmuştur.

Tablo 1: Ölçeğe İlişkin Güvenilirlik Test Sonuçları

\begin{tabular}{rrrr}
\hline Cronbach's Alfa & Standartlaştırılmış Cronbach's Alfa & N \\
\hline, 741 & &, 731 & 10 \\
\hline
\end{tabular}

Çalışmada güvenilirlik analizi için temel analiz olan Cronbach Alpha $(\alpha)$ kullanılmıştır. Benlik saygısı düzeyinin belirlenmesinde Rosenberg Benlik Saygısı Ölçeğinin her bir maddesi (10 soru) için tek bir $\alpha$ değeri olabileceği gibi, tüm soruların ortalama bir $\alpha$ değeri de olabilir. Tüm sorular için elde edilen $\alpha$ değeri o anketin toplam güvenilirliğini gösterir ve 0.7 'den büyük olması beklenir, düşük $\alpha$ değerleri anketin zayıf güvenilirliği olduğunu gösterir, $\alpha>0.8$ olması ise anketin yüksek güvenilirliğe sahip olduğunu göstermektedir. Tablo 1 de görüldüğü Cronbach Alpha $(\alpha)$ 0.741 büyük olduğu için anketin güvenirliliğinin iyi olduğunu göstermektedir. 


\begin{tabular}{lrrrrrrrr}
\hline & & & \multicolumn{5}{c}{ Maksimum / } \\
& Ortalama & Minimum & Maksimum & Aralk & Minimum & Varyans & N \\
\hline Ög. Ort. & 2,529 & 1,808 & 3,179 & 1,372 & 1,759 &, 133 & 10 \\
\hline
\end{tabular}

\section{Ölçek İstatistikleri}

\begin{tabular}{crrrr}
\hline Ortalama & Varyans & Std. Sapma & N & \\
\hline 25,2949 & 27,613 & 5,25483 & 10 \\
\hline
\end{tabular}

Tablo 2. Engellilik Durumuna Göre Ölçek Ortalamalarına İlişkin Normal Dağılım Analiz Sonuçları

\begin{tabular}{|c|c|c|c|c|c|c|c|}
\hline & \multirow[b]{3}{*}{ Katılımcılar } & \multicolumn{6}{|c|}{ Olay } \\
\hline & & \multicolumn{2}{|c|}{ Geçerli } & \multicolumn{2}{|c|}{ Eksik } & \multicolumn{2}{|c|}{ Toplam } \\
\hline & & $\mathrm{N}$ & Yüzde & $\mathrm{N}$ & Yüzdet & $\mathrm{N}$ & Yüzde \\
\hline \multirow[t]{2}{*}{ Benlik Saygısı } & Engelsiz & 39 & $100,0 \%$ & & $0,0 \%$ & 39 & $100,0 \%$ \\
\hline & İşitme Engelli & 39 & $100,0 \%$ & & $0,0 \%$ & 39 & $100,0 \%$ \\
\hline
\end{tabular}

Betimlemeler

\begin{tabular}{|c|c|c|c|c|c|}
\hline & Katılımcilar & & & İstatistik & Std. Hata \\
\hline \multirow[t]{19}{*}{ Benlik Saygıs1 } & \multirow[t]{13}{*}{ Engelsiz } & \multicolumn{2}{|l|}{ Ortalama } & 2,5744 & ,06056 \\
\hline & & Ortalama için \%95 Güven & Alt Sinır & 2,4518 & \\
\hline & & Aralığg1 & Üst Sınır & 2,6969 & \\
\hline & & \multicolumn{2}{|l|}{ 5\% Ayıklanmış Ortalama } & 2,5799 & \\
\hline & & \multicolumn{2}{|l|}{ Ortanca Değer } & 2,6000 & \\
\hline & & \multicolumn{2}{|l|}{ Varyans } &, 143 & \\
\hline & & \multicolumn{2}{|l|}{ Std. Sapma } & ,37817 & \\
\hline & & \multicolumn{2}{|l|}{ Minimum } & 1,80 & \\
\hline & & \multicolumn{2}{|l|}{ Maksimum } & 3,20 & \\
\hline & & \multicolumn{2}{|l|}{ Aralık } & 1,40 & \\
\hline & & \multicolumn{2}{|l|}{ Çeyrek Değerler Genişliği } &, 50 & \\
\hline & & \multicolumn{2}{|l|}{ Çarpıklık (Skewness) } &,- 344 & ,378 \\
\hline & & \multicolumn{2}{|l|}{ Basıklık (Kurtosis) } &,- 384 & ,741 \\
\hline & \multirow[t]{6}{*}{ İşitme Engelli } & \multicolumn{2}{|l|}{ Ortalama } & 2,5744 & 10283 \\
\hline & & Ortalama için $\% 95$ Güven & Alt sinır & 2,2764 & \\
\hline & & Aralığg1 & Üst Sınır & 2,6928 & \\
\hline & & 5\% Ayıklanmış Ortalama & & 2,4996 & \\
\hline & & Ortanca Değer & & 2,4000 & \\
\hline & & Varyans & & ,412 & \\
\hline
\end{tabular}




\begin{tabular}{lrr}
\hline Std. Sapma &, 64217 & \\
Minimum & 1,20 & \\
Maksimum & 3,50 & \\
Aralık & 2,30 & \\
Çeyrek Değerler Genişliği &, 80 & \\
Çarpıklık (Skewness) &,- 260 &, 378 \\
Basıklık (Kurtosis) &,- 598 &, 741 \\
\hline
\end{tabular}

\section{Normallik Testleri}

\begin{tabular}{llccccccr}
\hline & & \multicolumn{3}{c}{ Kolmogorov-Smirnov $^{\mathrm{a}}$} & \multicolumn{3}{c}{ Shapiro-Wilk } \\
\cline { 3 - 9 } & Katılımc1lar & İstatistik & $\mathrm{df}$ & $\mathrm{p})=$ Sig. & İstatistik & $\mathrm{df}$ & $(\mathrm{p})=$ Sig. \\
\hline \multirow{2}{*}{ Benlik sayg1s1 } & Engelsiz &, 117 & 39 &, 198 &, 956 & 39 &, 129 \\
& İşitme Engelli &, 105 & 39 &, $200^{*}$ &, 961 & 39 &, 196 \\
\hline
\end{tabular}

*. Bu, gerçek değerin bir alt sınırıdır.

a. Lilliefors değer düzeltmesi

Tanımlayıcı istatistik kısmında normal dağılım testi için ortalama değeri (mean) ve median (medyan) değerinin birbirine yakın sonuçlar olması, veri setinin normal dağılıma sahip olduğunu göstermektedir. Çalışmada görüldüğü gibi ortalama değerimiz 2,5744 ve medyan değerinin 2,4000 olarak görülmektedir. Bu verilere göre veri setinin normal dağ $11 ı \mathrm{~m}$ olarak düşünülmektedir.

Skewness (Çarpıklık) ve Kurtosis (Basıklık) değeri normal dağılım testi için bakılması gereken iki değer. Skewness ve Kurtosis değerlerinin normal dağılımı göstermesi için 0 ya da 0 'a en yakın değerlere sahip olması gerekmektedir.

Tablo 3. Engellilik Durumuna Göre Farklılık Olup Olmadığına İlişkin ANOVA (Normal Dağılım) Analiz Sonuçları

\section{Betimlemeler}

\begin{tabular}{|c|c|c|c|c|c|c|c|c|}
\hline \multirow[b]{2}{*}{$\underline{B e n l i k ~ S a y g 1 s 1}$} & \multirow[b]{2}{*}{$\mathrm{N}$} & \multirow[b]{2}{*}{ Ortalama } & \multirow{2}{*}{$\begin{array}{c}\text { Std. } \\
\text { Sapma }\end{array}$} & \multirow{2}{*}{$\begin{array}{l}\text { Std. } \\
\text { Hata }\end{array}$} & \multicolumn{2}{|c|}{ rtalama için $\% 95$ Güven Aralığ } & \multirow[b]{2}{*}{ Min } & \multirow[b]{2}{*}{ Mak } \\
\hline & & & & & Alt Sinir & Üst Sinır & & \\
\hline Engelsiz & 39 & 2,5744 & ,37817 &, 06056 & 2,4518 & 2,6969 & 1,80 & 3,20 \\
\hline İşitme Engelli & 39 & 2,4846 & ,64217 &, 10283 & 2,2764 & 2,6928 & 1,20 & 3,50 \\
\hline Toplam & 78 & 2,5295 &, 52548 &, 05950 & 2,4110 & 2,6480 & 1,20 & 3,50 \\
\hline
\end{tabular}

Varyansların Homojenlik Testi

\begin{tabular}{lrrrrrrr}
\hline & Levene İstatistik Testi & df1 & df2 & (p)=Sig. & \\
\hline Benlik Saygis1 & 8,597 & 1 & 76 & &, 004 \\
\hline
\end{tabular}




\begin{tabular}{lrrrlll}
\hline \hline Benlik Saygıs1 & Kareler Toplamı & df & Ortalama Kare & F & (p)=Sig. & \\
\hline Guruplar Aras1 &, 157 & 1 &, 157 &, 566 & &, 454 \\
Guruplar İçi & 21,105 & 76 &, 278 & & \\
\hline Toplam & 21,262 & 77 & & & \\
\hline
\end{tabular}

ANOVA tablosunda en sonraki $(p)=$ sig. değeri 0,05 büyük olduğu için işitme engelli hentbolcular ve işitme engelli olmayan hentbolcuların karşılaştırılan ortalamaları arasında anlamlı bir fark olmadığını göstermektedir.

\section{Tartışma}

İşitme engelli hentbolcular ile işitme engeli olmayan hentbolcuların benlik saygısı düzeylerinin incelenmesidir. İşitme engelli sporcular ve işitme engeli olmayan hentbolcular arasında benlik saygısı açısından anlamlı bir farklılık bulunamamıştır.

Mars ve arkadaşları (1986) tarafından yapılan bir çalışmada, dağcılık programına katılan kişilerin benlik kavramlarının geliştiğini, Miller tarafından yapılan çalışmada da (1988), yüzme programına katılan 9-14 yaşındaki çocukların benlik kavramlarının geliştiğini ortaya koymuşlardır.

Başka bir çalışmada, dans aktivitesine katılım ile benlik saygısı arasında olumlu bir ilişkinin olduğu, bu olumlu ilişkinin dansın duyguları ve duyguları ifade etme firsatı sağlaması gerçeğinden de kaynaklanabileceğini ileri sürülmüştür (Kurková ve Jayne Maertin, 2014). Strassel, Cherkin, Steuten, Sherman ve Vrijhoef (2011) tarafından yapılan bir çalışmada, dans terapisinin, yaşam kalitesi, benlik saygısı veya engelli insanlar için hastalıklarla başa çıkmada ve iyileşmelerde olumlu etkilerini ortaya koymuşlardır. Diğer yandan dans terapisi teorisi, beden ve zihnin birbirini etkilediğini varsayar, böylece hareketteki bir değişiklik insanın işleyişini etkiler ve hareket kişiliği yansitır (Mecums, 1998).

Bazı araştırmalar akademik başarının benlik saygısını olumlu etkilediğini öne sürerken, diğerleri bunun tam tersini savunuyor. Valley (1992), egzersiz yapmanın benlik saygisına olumlu etkisinin olduğunu, Liu vd. (1992) 'e göre; benlik saygısı ile akademik başarı arasında pozitif bir korelasyon olduğunu iddia ederken, Hewitt'in (1998) çalışması benlik saygısı ile akademik başarı arasındaki bu ilişkinin oldukça zayıf olduğunu ve yüzeysel olarak yorumlandığını göstermektedir (Liu vd., 1992).

Rusu ve Rusu, (2017) ile Shapiro ve Martin'in (2010) tarafinyan yapılan araştırmalar sonucunda insanlar arasında benlik saygısını geliştirmenin bir yolunun arkadaşlık kurmak ve sosyal destek almakla ilgili fiziksel aktivitelere katılmak olduğunu ileri sürmüşlerdir. Bu katılım sayesinde çocuklar yeni akranlarla tanışma ve yeni arkadaşlıklar kurma fırsatını yakalamışlardır. Buda organize fiziksel aktivitelere katılma sürecinde kurulan sosyal ilişkilerin engellilerin izolasyon duygusu üzerindeki olumlu etkisi ortaya koymuştur.

Chen vd. (2012) ile Daniel ve Leaper (2006) tarafından yapılan çalışmalarda ergenlerin daha yüksek seviyelerde spora katılımının, düşük depresyon seviyeleriyle bağlantılı olan benlik saygısını olumlu yönde etkilediğini ortaya koymuşlardır. Organize sporlar, atletik becerileri, akran ilişkilerini ve akademik olmayan yetkinlikleri öğrenme firsatları sunarak (Smith, 2003) olumlu genç gelişimine katkıda bulunur ve böylece daha fazla benlik saygısı ile sonuçlanır (Chen vd., 2012). Ayrıca, Bowker (2006) tarafından yapılan bir çalışmada spora katılımın, fiziksel yeterlilik duygularını ve fiziksel görünümden duyulan memnuniyeti artırabildiğini ortaya koymuştur. Sporun, ergenlerin benlik duygusunun önemli bir parçası olan bir başarı duygusu sunduğu anlamına gelir. Örneğin, kişinin ekstra çabalarının ödüllendirildiğini görmesi ve kişinin kısa veya uzun vadeli hedeflerine ulaşması, benlik saygısı bedeni oluşturabilir. 
$\mathrm{Bu}$ çalışmada; spor yapan işitme engelli ve spor yapan işitme engelli olmayan kontrol gurubunda ki sporcular arasında benlik saygısına bakıldığında, anlamlı bir farklılı̆̆ın görülmediği anlaşılmıştır. Bu da spor yapmanın benlik saygısının gelişiminde önemli derecede olumlu etki yarattığını göstermektedir.

\section{Sonuç}

Engelli ve engelli olmayan hentbolcular arasında benlik saygısı açısından anlamlı bir fark bulunup bulunmadığına bakıldığında, anlamlı bir farklılık bulunamamıştır, dolayısı ile sonuçlar spor yapan işitme engelli sporcuların benlik saygısının gelişimine yardımcı olduğunu göstermektedir.

Elde edilen bulgular neticesinde farklı yaşam alanlarında bulunan işitme engelli hentbolcuların özgüven düzeylerinin benzer düzeylerde olduğu söylenebilir. Değişkenler arasında anlamlı farklılık bulunmaması önem arz etmektedir. Bu durum söz konusu sonuçların daha fazla incelenmesinin gerekliliğini ortaya koymaktadır. İşitme engelli bireyler de yapılan çalışmaların birbiriyle çelişkili olması tartışmaya açık bir konu haline gelmiştir, bu nedenle yeni ve daha fazla çalışmaların yapılması gerekliliği sonucunu ortaya çıkmaktadır.

\section{Kaynakça}

Adams, S.G., Gullotta T. (1989). Adolescent life experiences. Brooks Cole Publishing Company.

Benjet, C., \& Hernández Guzmán, L. (2001). Gender differences in psychological well-being of Mexican early adolescents. Adolescence, 36(141), 47-65.

Bowker, A. (2006). The relationship between sports participation and self-esteem during early adolescence. Canadian Journal of Behavioural Science, 38, 214-229. https://doi.org/10.1037/cjbs2006009

Chen, W., Chen, C., Lin, Y., \& Chen, T. (2012). Sport participation and self-esteem asmediated by perceived peer acceptance and sport self-concept in Taiwanese college students. Social Behavior and Personality: An International Journal, 40, 699-704. https://doi.org/10.2224/sbp.2012.40.4.699

Daniel, E., \& Leaper, C. (2006). A longitudinal investigation of sport participation, peeracceptance, and self-esteem among adolescent girls and boys. Sex Roles, 55, 875-880. https://doi.org/10.1007/s11199-006-9138-4

Dzwonkowska, I., Lachowicz-Tabaczek, K., \& Laguna, M. (2008). Samoocena i jej pomiar. Skala samooceny SES M.

Fan, F., \& Fu, J. (2001). Self-concept and mental health of college students. Chinese Mental Health Journal, 15, 76-77.

Fellinger, J., Holzinger, D., \& Pollard, R. (2012). Mental health of deaf people. The Lancet, 379 (9820), 1037-1044. https://doi.org/10.1016/S0140-6736(11)61143-4

Frost, J., \& McKelvie, S. (2004). Self-esteem and body satisfaction in male and female elementary school, high school, and university students. Sex Roles: A Journal of Research, 51 (1-2), 45-54. https://doi.org/10.1023/B:SERS.0000032308.90104.c6

Garaigordobil, M., Cruz, S., \& Pérez, J.I. (2003). Análisis correlacional y predictivo del autoconcepto con otros factores conductuales, cognitivos y emocionales de la personalidad durante la adolescencia. Estudios de Psicología, 24, 113-134. 
Garaigordobil, M., Pérez Fernández, J., \& Mozaz, M. (2008). Self-concept, self-esteem and psychopathological symptoms. Psicothema. 20, 114-23.

González de Rivera, J.L., De las Cuevas, C., Rodríguez Abuín, M., \& Rodríguez Pulido, F. (2002). SCL-90-R, Symptom Cheklist 90 Revised, Spanish adaptation. TEA.

Gutiérrez, O., Luciano, M.C., \& Valdivia, S. (2005). Change of self-efficacy verbalizations and derivation of functions. Psicothema, 17(4), 614-619.

Haugen, T., Ommundsen, Y., \& Seiler, S. (2013). The relationship between physical activity and physical self-esteem in adolescents: The role of physical fitnessindices. Pediatric Exercise Science, 25(1), 138-153.https://doi.org/10.1123/pes.25.1.138

Hopyan, T., Gordon, K.A., \& Papsin, B.C. (2011). Identifying emotions in music through electrical hearing in deaf children using coch learim plants. Cochlear Implants International, 12(1), $21-26$.

Knox, E., \& Muros, J.J. (2017). Association of life style behaviours with self-esteem through health-related quality of life in Spanish adolescents. European Journal of Pediatrics, 176(5), 621-628. https://doi.org/10.1007/s00431-017-2886-z

Kurková, P., \& Jayne Maertin, J. (2014). The benefits of square dancing as a means of physical activity for Czech dancers with hearing loss. Acta Gymnica, 44(4), 223-230. https://doi.org/10.5507/ag.2014.023

Lameiras, M., \& Rodríguez, Y. (2003). Age and sex differences in self-esteem among Spanish adolescents. Psychological Reports, 93, 876-878.

Lesar, I., \& Smrtnik Vituli, H. (2014). Self-esteem of deaf and hard of hearing students in regular and special schools. European Journal of Special Needs Education, 29(1), 59-73. https://doi.org/10.1080/08856257.2013.849842

Liu, X., Kaplan, H.B, \& Riser, W. (1992). Decomposing the reciprocal relationships between academic achievement and general self-esteem. Youth and Society, 24, 123-148.

Lu, A., Hong, X., Yu, Y., Ling, H., Tian, H., Yu, Z., et al. (2015). Perceived physical appearance and life satisfaction: A moderated mediation model of self-esteem and life experience of deaf and hearing adolescents. Journal of Adolescence, 39, 1-9.

Maite, G., José, I.P., María, M. (2008). Self-concept, self-esteem and psychopathological symptoms. Psicothema, 20(1), 114-123.

Matud, P., Ibáñez, I., Marrero, R., \& Carballeira, M. (2003). Diferencias en autoestima en función del género. Análisis y Modificación de Conducta, 29, 51-78.

Mecums, B. (1998). Dance movement therapy. Thousand Oaks, Sage Publications Inc.

Muth, J.L., \& Cash, T.F. (1997). Body-image attitudes: What difference does gender make? Journal of Applied Social Psychology, 27, 1438-1452. .https://doi.org/10.1111/j.15591816.1997.tb01607.x

Nemček, D. (2017). Self-esteem in people with physical disabilities: Differences between active and inactive individuals. Acta Facultatis Education is Physicae Universitatis Comenianae, 57(1), 34-47. https://doi.org/10.1515/afepuc-2017-0004

Noordstar, J.J., van der Net, J., Jak, S., Helders, P.J, Jongmans, M.J. (2016). The change in perceived motor competence and motor task values during elementary school: A longitudinal cohort study. British Journal of Developmental Psychology, 34(3), 427-46. doi: 10.1111/bjdp.12142 
Pastor, Y., Balaguer, I., \& García-Merita, M. (2006). Relacionesentre el autoconcepto y el estilo de vida saludable en la adolescencia media: un modelo exploratorio. Psicothema, 18(1), 1824.

Rosenberg, M. (1965). Society and the adolescent self image. Princeton University Press.

Rusu, O., \& Rusu, D. (2017). Social integration through sport to hearing impaired students. Sport in Society, 17(2), 41-52.

Scarpa, S. (2011). Physical self-conceptand self-esteem in adolescents and young adults with and without physical disability: The role of sports participation. European Journal of Adapted Physical Activity, 4(1), 38-53.

Shapiro, D.R., \& Martin, J.J. (2010). Athletic identity, affect and peer relations in youth athletes with physical disabilities. Disability and Health Journal, 3, 79-85. https://doi. org/10.1016/j.dhjo.2009.08.004

Sonstroem, R.J.,\& Morgan, W.P. (1989). Exercise and self-esteem: Rationale and model. Medicine and Science in Sports and Exercise, 21(3), 329-337. https://doi.org/10.1249/00005768198906000-00018

Strassel, J. K., Cherkin, D. C., Steuten, L., Sherman, K.J., \& Vrijhoef, H.J. M. (2011). A systematic review of the evidence fort he effectiveness of dance therapy. Alternative Therapies in Health and Medicine, 17(3), 50-59.

Uchida, W., Marsh, H., \& Hashimoto, K. (2015). Predictors and correlates of self-esteem in deaf athletes. European Journal of Adapted Physical Activity, 8(1), 21-30.

Watson, D.C. (1998). Therelationship of self-esteem, locus of control and dimensional models to personality disorders. Journal of Social Behaviorand Personality, 13, 399-420.

Wilgenbush, T., \& Merrel, K.W. (1999). Gender differences in self-concept among children and adolescents: A meta analysis of multi dimensional studies. School Psychology Quarterly, $14,101-120$.

Yuang, X. (2000). Correlation between self-esteem and mental health of secondary normal school students. Chinese Journal of Clinical Psychology, 8, 102-103.

\section{Beyan ve Açıklamalar (Disclosure Statements)}

1. Araştırmacıların katkı oranı beyanı / Contribution rate statement of researchers: Birinci Yazar/First author \% 80, İkinci Yazar/Second author \% 20

2. Yazarlar tarafından herhangi bir çıkar çatışması beyan edilmemiştir (No potential conflict of interest was reported by the authors). 